\title{
Facing Terrorism Alone ${ }^{1}$
}

Carolyn S. Wilken ${ }^{2}$

The threats of terrorism have left us all fearful and anxious. American's stress level is up and people talk about being anxious and afraid. We worry about the possibility of another terrorist attack. We feel stressed because we don't know what to expect from day to day.

This is a particularly difficult time for older adults who live alone. While older adults have family and friends to turn to, there are times when it is just scary to live alone. It can be especially frightening when you are an older adult.

Many of us play the "what if" game with ourselves.

- What if there was another terrorist attack?

- What if there was Anthrax in the mail again?

- What if I couldn't get in touch with my family?

- What if I had to run out of a building? I'm pretty slow at my age.

- What if...

- What if...

And so we worry. And we feel stressed and anxious. We are anxious because terrorism is completely out of our control. Sometimes we simply wring our hands and wonder what can we do? The truth is we can't do anything about terrorism, but we can do something to control our worrying. Below are some simple strategies to reduce stress and anxiety. Of course these strategies won't make all the fear go away, but by following these suggestions you can regain control over your life -no matter what your age.

1. Do one thing at a time.

Do you sometimes have problems finishing things you've started. Is it difficult to concentrate? Do you find yourself constantly drawn to the television to get the latest news? You aren't alone if you find yourself glued to the TV. In fact, doing this has become so common that it has a name: This is called the CNN Effect.

Are you so wrapped up in what's happening that you lose track of your usual work and daily tasks. Suddenly you are faced with a mountain of unfinished tasks, and the next thing you know, you are stressed about the things you haven't done.

Specialists suggest that doing one thing at a time, and completing that project before beginning another is a good way to help gain control over stress. Choose one task that needs to be done right away, and do it! Then take on the next one. Checking these things off a list is a great stress reducer.

1. This document is FCS9199, one of a series of the Department of Family, Youth and Community Sciences, Florida Cooperative Extension Service, IFAS, University of Florida, Gainesville FL 32611. First published: May 2003. Reviewed by Elizabeth Bolton, Ph.D., Department of Family, Youth and Community Sciences, Gainesville, Florida, 32611. Please visit the EDIS Web site at http://edis.ifas.ufl.edu

2. Carolyn S. Wilken, Ph.D., associate professor, Department of Family, Youth and Community Sciences, University of Florida, Gainesville Florida, 32611. 
2. Keep a routine

One of the most effective ways to reduce stress is to keep your normal routine. It is sometimes hard to do that when you have other things -such as terrorism- on your mind. Having a routine is a way to maintain control in your life. With the constant threat of terrorism it feels like there isn't much that you can control right now. But stress and anxiety become manageable when you work to control the things you can. Try these tips.

- Maintain your regular sleep schedule

If you are staying up later than normal to watch the latest news, you may not be getting enough sleep. And, for many people, "watching the war" right before going to bed is like eating spicy food late at night -you just don't sleep very well!

\section{- Eat regularly and well}

During times of stress some people say that they just can't eat... while others use eating in an effort to reduce their feelings of stress. Focus on the healthy foods you enjoy, but reconsider any plans to make drastic changes in your eating habits when you are feeling so stressed. In time, we will again feel normal and then we can make such changes.

\section{- Exercise is a stress-buster}

Fresh air and exercise are well known stress busters. Take a walk alone, or better yet with friends. Walking will clear your head and improve your health. People who exercise feel more confident and stronger. And, they sleep better too.

\section{- Keep your usual schedule}

Stick with your regular schedule. If you usually buy groceries on Monday, volunteer of Wednesday, clean on Friday and attend religious services on Saturday or Sunday, keep it up. Keeping your usual schedule helps you maintain some control in your life and prevents you from becoming obsessed with terrorism. People who miss their regular activities because they are afraid to leave home can easily become isolated, lonely, and in the end, even more stressed and anxious.

3. Maintain contact with friends and family

On September 11, 2001 Americans jammed the phone lines as they reached out to family and friends. We reached out to be sure that everyone was 'ok', and we were reaching out to find someone who could to tell us that everything was going to be okay. Most Americans are still somewhat worried about their own safety, and about their friends and loved ones.

\section{- Keep in touch}

Sharing joys as well as concerns is a great stress reducer. Sometimes talking to people about your fears and concerns really helps. Talking also helps us as we try to better understand what is happening in the world. But a word of warning is important. Be wary of the "gloomers and doomers" whose negative talk may increase instead of decrease your stress and anxiety. Learn to change the subject, ("Have I told you about my grandchildren"?) or walk away if you find a conversation is increasing your stress level.

\section{- Know your neighbors}

Many people have close ties and friendships with their neighbors and know each other well enough to be aware of any special needs someone might have. Close neighbors also know who is older, and who is alone. Unfortunately, our neighbors are strangers. Now is a good time to get to know your neighbors. It's a time to learn who you could turn to in time of need, and to let others know that you are available to help as well. 
4. Talk to yourself

\section{- Listen first, then talk to yourself}

Gather the information about what you should do to be prepared for a terrorist attack. Talk to family and friends, read the papers and the Internet, and watch the news. Then, ask yourself what you need to do to feel as safe as you can. Make a plan. If you need help in carrying out your plan ask for it. Family and friends may be able to help you. You can also contact your area for advice: Contact your local Red Cross, emergency management office, or local law enforcement agency.

- Moving on...the hardest part

Once you've thought this all through and set up your safety plan it's time to let go. Ask yourself: "Is there anything more I can do?" If you've done all you can, then relax a little and get on with life.

\section{Conclusion}

If you have done everything you can to protect yourself and are still feeling stressed and anxious then you may want to ask a professional for help in finding other ways to reduce your stress. Call your physician, speak with your clergy person, or contact the mental health department for guidance.

This paper offered some suggestions for reducing the stress in our lives. We can focus on doing one thing at a time. We can keep our regular schedules and routines. We must keep in touch with our family and friends. And we can listen to and talk to ourselves about our fears. And finally, we can get help when are stress, anxiety and worry become more than we can handle. Being alone may be especially hard these days, but taking control wherever we can is a great stress reducer. 